\title{
AAIUnB e a Maloca-UnB: Presença e Espacialidade Indígena no Campus Darcy Ribeiro
}

\section{AAIUnB and Maloca: Indian presence and spatiality in campus Darcy Ribeiro}

\author{
Victoria Miranda da Gama Oliveira \\ Universidade de Brasília - UnB \\ e-mail:vicmgama@gmail.com
}

\begin{abstract}
Resumo
A criação da Associação dos Acadêmicos Indígenas da Universidade de Brasília (AAIUnB), em 2008, e do Centro de Convivência Multicultural dos Povos Indígenas (Maloca-UnB) em 2010, no Campus Darcy Ribeiro da Universidade de Brasília (UnB) sugere a conquista de espaços de ação político-étnica dentro da estrutura cultural universalizante do ensino superior brasileiro. Esta análise se embasa nos conceitos de espaço, de ação política e de interculturalidade crítica. A revisão documental, a observação participante, bem como as entrevistas abertas foram os instrumentos metodológicos que facilitaram a coleta de dados empíricos. Como resultados, destaca-se que a UnB instituiu, pioneiramente, em 1990, um edital específico para garantir o ingresso dos indígenas. A presença acadêmica, política e organizacional dos indígenas nessa universidade revela-se fundamental para evidenciar os desafios da institucionalização, nem sempre dinâmica, de políticas universitárias que garantam acesso e permanência desse grupo social.
\end{abstract}

Palavras-chave: Maloca, estudantes indígenas, ensino superior, Lei de cotas, interculturalidade.

\begin{abstract}
The creation of the "Associação dos Acadêmicos Indígenas da Universidade de Brasília" (AAIUnB), in 2008, and the creation of the "Centro de Convivência Multicultural dos Povos Indígenas" (Maloca), in 2010, in the Campus Darcy Ribeiro of the University of Brasilia (UnB) suggest the achievement of spaces of ethnical-political action inside of the universalizing cultural structure of higher Brazilian education. This analysis is based on concepts of space, political action and critical interculturality. The documental review, the eyewitness observation and the open interviews were the methodological instruments which made the empirical data collection easier. As the results, it is highlighted that UnB established, in 1990 , in a pioneering way, a specific edict to guarantee the Indian entrance in the university. The academical, political and organizational Indian presence at this university shows itself as fundamental to expose the challenges of institutionalization of university politics, which is not always dynamic, to guarantee their access and permanence.
\end{abstract}

Keywords: Maloca, Indian students, higher education, "Cotas" law, interculturality. 


\section{Introdução}

A pesquisa que originou os dados aqui analisados buscou compreender as dinâmicas de engajamento indígena no campus Darcy Ribeiro, na Universidade de Brasília, localizado na capital brasileira. Este artigo analisa a criação da Associação dos Acadêmicos Indígenas da Universidade de Brasília (AAIUnB) e do Centro de Convivência Multicultural dos Povos Indígenas (Maloca UnB), como indicativos político-espaciais da presença dos estudantes indígenas nessa instituição. A análise se orienta pela seguinte questão: a AAIUnB e a Maloca UnB são desdobramentos das políticas públicas de inclusão ao ensino superior, promovidas na primeira década do século XXI no Brasil?

Essa iniciativa governamental buscou incentivar o acesso dos povos indígenas e outros segmentos sociais vulneráveis e marginalizados desse espaço até então elitizado. Será que essa dinâmica também derivou em embates e tensões? Sabe-se que o espaço acadêmico naturalizou a sua lógica excludente encenando-se como veículo de saberes ditos universais (Carvalho 2012) e fundamentados nos padrões da civilização ocidental.

Nessa trilha, indaga-se também se a AAIUnB e o Maloca UnB contribuem visibilizando manifestações interculturais, troca de conhecimentos e aproximação entre agentes sociais diferenciados social, econômica, política, cultural e academicamente na cena universitária. Questiona-se ainda de que se compõe o cotidiano desse centro de convivência e dessa associação, quais as possibilidades e limites no tocante à promoção da diferença cultural e de validação de outros saberes no contexto da UnB. Somado a isso, em que medida essa presença indígena na UnB se traduz em ações institucionalizadas para enfrentar o desafio dessa universidade plenamente pluricultural?

A presença atual dos indígenas no ensino superior constitui-se como ação política sempre que contextualizada na historicidade da demanda indígena pelo direito constitucional de acesso à educação (SOUSA, 2009). É nessa perspectiva que o antropólogo indígena Baniwa, Gersem dos Santos (2009), defende que o diploma universitário é um instrumento de luta política no contexto interétnico contemporâneo. Segundo Arcanjo (2011), a afirmação e a valorização das diferenças étnicas em contextos nacionais podem ser impulsionadas mediante mudanças estruturais nas políticas educacionais.

Nesse sentido, o conceito de interculturalidade crítica (WALSH, 2012) parece eficaz para dimensionar o desafio da mudança social a partir da inserção de estudantes indígenas no ensino superior brasileiro. Para a autora, a 
interculturalidade pode ser percebida como a possibilidade de diálogo entre as culturas, partindo do problema estrutural-colonial-racial, através do reconhecimento de que a diferença se constrói dentro de uma matriz colonial de poder racializado e hierarquizado.

O conceito de espaço nesta análise reforça a dimensão espacial como representação e valor simbólico. Sob essa ótica, o "espaço não é a cristalização do fenômeno, mas parte das possibilidades relacionais do mesmo. Assim, construímos imagens do espaço e atribuímos a elas as representações de nossa existência" (GIL FILHO, 2001, p. 7). Nos espaços, marcados pelo confronto de forças, a resistência se torna fundamental na busca por sociedades mais justas e igualitárias (GORELIK, 2004). Isto é, o espaço é compreendido a partir de conflitualidades. O espaço político é pensado como símile ao teatro, indicando-o como local de uma "representação" (CODATO, 2011).

A pesquisa em questão tomou como norteadores metodológicos a revisão bibliográfica, a análise documental sobre a criação da Maloca, a observação participante durante os eventos ali realizados e a realização de entrevistas abertas com estudantes indígenas da UnB. O exercício analítico das narrativas coletadas se apoiou na análise de discurso crítica, a qual enfatiza o contexto de produção e a dialogicidade entre as fontes consultadas (RESENDE e RAMALHO, 2009) e nos conceitos de interculturalidade (WALSH, 2012), espaço (CODATO, 2011), no debate sobre a implementação da Lei de cotas no Brasil (COELHO, 2006) e nos avanços, empecilhos e desafios impostos pela presença indígena na UnB (GERVÁSIO, 2016, CRUZ, 2016). Além da introdução e da conclusão, este artigo dedica um item à descrição do processo de inserção dos estudantes indígenas nas universidades brasileiras, se analisa a criação da AAIUnB, e a descrição analítica da concepção e construção da Maloca UnB.

\section{Presença indígena na UnB}

Os estudantes indígenas entrevistados afirmam que "em 2006 já tinha estudantes indígenas aqui na UnB [...]. Não tinha programa para nada, nada em específico para indígenas. Então surgiu a ideia de que criar uma associação que poderia nos favorecer [...]" (Entrevista $\mathrm{n}^{\circ} 1$, Maloca, 26/04/2017). Afirmam ainda que os avanços conseguidos são fruto da constante reivindicação indígena, "porque tudo o que a gente conseguiu aqui não foi porque a UnB quis ou porque ela é boazinha. Foi depois de muita luta" (Entrevista ${ }^{\circ}$ 2, Maloca UnB, 26/04/2017). 
As narrativas dos entrevistados alertam para o silenciamento da agência indígena no discurso institucional y oficial. Denunciam que a universidade publicita os avanços desse convenio como se fossem produto somente do empenho das instituições envolvidas "para fora é tudo bonito, não é? [o discurso das instituições destaca e se orgulha em afirmar] a UnB foi a primeira a fazer o vestibular indígena" (Entrevista $n^{\circ} 2$, Maloca UnB, 26/04/2017). No entanto, os estudantes indígenas arcam com custos econômicos e sociais para garantir seu lugar na UnB, voltaremos nesse assunto nas páginas seguintes.

Até 2012 o ingresso dos indígenas nas universidades brasileiras era regulado por regras próprias em cada estado da Federação. Em 2004, na gestão do reitor Lauro Morhy, a Fundação da Universidade de Brasília (UNB) celebrou um convênio com a Fundação Nacional do Índio (Funai) para promover a inclusão de aproximadamente 200 estudantes indígenas no período entre 2001 a 2005. Iniciativa pioneira no âmbito de uma universidade federal, com a mediação política e financeira da Funai do Ministério de Educação (MEC), desvendou novos desafios e evidenciou a urgente necessidade de uma política nacional coesa e bem estruturada (SOUSA, 2009).

Esse convênio permitiu a realização, desde 2005 até 2013, do vestibular diferenciado para aspirantes indígenas. Porém, durante a gestão de Ivan Marques de Toledo Camargo, 2012-2016, esse edital não voltou a ser efetivado. Os estudantes indígenas criticam o silencio institucional quando a UnB "ficou muito tempo sem fazer o vestibular [desde 2013 até 2016] (Entrevista $\mathrm{n}^{\circ}$ 2, Maloca UnB, 26/04/2017). afirmam ter requerido formalmente a continuidade desse edital, sem sucesso "quando nós temos algo para pedir para a reitora [da UnB], a gente faz um documento, protocola lá através da nossa associação [...]. Na gestão anterior [Ivan Marques de Toledo Camargo], a gente já estava lá pressionando, mas não deram atenção para nós. Acho que jogavam nossas reivindicações na gaveta [...] (Entrevista $\mathrm{n}^{\circ}$ 1, Maloca, 26/04/2017).

A aprovação da Lei $n^{\circ} 12.711$ de 2012, conhecida como Lei de cotas, representou um avanço na inclusão social dos indígenas ao ensino superior brasileiro (SANTOS, 2011), pois determinou a obrigatoriedade da reserva de vagas nas universidades e institutos federais atendendo aos critérios de discriminação positiva cor, etnia e renda. Assim, o governo da presidenta Dilma Roussef estabeleceu uma política nacional de ações afirmativas para o ingresso ao ensino superior. Trata-se de um "momento ímpar, histórico, transformador e necessário" ainda que o ingresso de cerca de 400 estudantes negros a cada vestibular represente apenas "uma gota d'água no oceano da dívida social" (CONSELHEIRO, 2006, p. 97). 
Em sociedades desiguais como as latino-americanas política de ações afirmativas não representam a única forma de luta pelo reconhecimento e redistribuição (cf. FRASER, 2001; 2002), mas refletem a necessidade de mudança profunda na gramática dos discursos universalistas das universidades, na sua estrutura burocratizada e nos projetos políticopedagógicos diante das demandas políticas e sociais contemporâneas. De acordo com Conselheiro (2006), a política de cotas abriu espaço para a discussão de novas questões e desafios para o Ensino Superior no século XXI.

O ensino superior possibilita novas condições sociais de poder, conhecimento e ser, assumindo o papel histórico e político na transformação social. Do ponto de vista político, trata-se de uma oportunidade de conhecer a sociedade hegemônica e instrumentalizar dito conhecimento das arenas em que os confrontos (CARVALHO, 2014) civilizatórios se reproduzem. Porém, os estudantes indígenas da UnB vivenciam empecilhos intransponíveis no tocante a inclusão $e$ permanência, como conflitos de convivência com discentes professores, funcionários e demais sujeitos do campus universitário.

As universidades brasileiras historicamente privilegiaram o ingresso de estudantes com renda média de oito salários mínimos (HERINGER, 2006). Nesse contexto, a renda familiar torna-se um aspecto sensível à permanência dos estudantes de segmentos sociais em situação vulnerável tornando-se fundamentais os programas ou subsídios que atinjam essas barreiras socioeconômicas (WELLER, 2007). Os indígenas entrevistados refletem enquanto a esse empecilho: "a Diretoria de Desenvolvimento Social (DDS) é responsável por definir quem é realmente de baixa renda e se tem direito a bolsa auxílio-moradia'. [...]. Alguns dos nossos colegas não conseguem, algumas bolsas foram cortadas por muitos critérios que a DDS tem proposto [...] Na verdade, são de baixa renda, mas a DDS considera que não" (Entrevista n 1, Maloca, 26/04/2017).

Essas narrativas dos estudantes indígenas explicitam que depois de mais de uma década da sua presença na UnB, as normativas, os trâmites, e as instâncias universitárias onde esses processos são desenvolvidos ainda não mudaram sua lógica elitista e excludente. Por isso, os povos indígenas do Brasil demandam sistematicamente não apenas a abertura de vagas específicas, mas políticas que garantam a permanência. Segundo Sousa

\footnotetext{
${ }^{1}$ Trata-se de um programa de auxílio financeiro mensal oferecido para estudantes que se enquadrem nas seguintes condições: com renda familiar per capita não superior a um salário mínimo e meio; estar matriculado em cursos de graduação com carga horária média superior ou igual a cinco horas diárias; não ter ultrapassado dois semestres do tempo regulamentar do curso de graduação, em que estiver cursando; ser indígena ou quilombola.
} 
(2009), almejar uma graduação se alia a própria dinâmica de emancipação indígena, entendida como uma forma de qualificar-se para robustecer as lutas pelos direitos. Os indígenas da UnB interpelam pela ampliação, validação e circulação de outros saberes, pautados em diferentes bases cosmológicas, filosóficas e epistemológicas, que transcendam a matriz ocidental e colonial.

Contudo, trata-se de processos sociais complexos que derivam em embates e tensões. Nessas disputas ainda prevalece a luta pela efetivação da Lei de cotas. Conforme revelam as entrevistas, as tratativas para reabertura do edital indígena foram retomadas em abril de 2016, no âmbito do evento chamado " 2 a semana dos Acadêmicos indígenas da UnB", promovido pela da AAIUnB e lideranças indígenas reunidas em Brasília com ocasião do Acampamento Terra Livre (ATL):

Ano passado [2015] nós começamos com a discussão, só que entramos de férias e eles [na reitoria UnB] foram empurrando, aí disseram que teve a ocupação [protestos estudantis contra a PEC 55]. Mas aí falamos, vamos todo mundo para reitoria [...] todo mundo caracterizado, pintado e tal para ganhar força [...] a gente falou: "se não tiver vestibular nesse ano, a gente vai ocupar"[...]. Também teve o ATL [...] tinha várias lideranças para apoiar. E a gente marcou uma reunião com a reitora [...] vieram várias lideranças [...] aquela sala da reitora ficou muito lotada, mas é só assim que as coisas andam [...] o vestibular vai sair em novembro [2017]" (Entrevista n² 2, Maloca UnB, 26/04/2017).

As narrativas dos estudantes indígenas da UnB revelam entraves no atendimento das demandas colocadas pela sua presença no ensino superior. A UnB é desafiada a criar condições para a compreensão das especificidades e conflitualidades que os indígenas evidenciam. Sua presença e ativismo acadêmico e político visibiliza a importância do debate científico a partir de formas emancipatórias que favoreçam a superação dos processos de sujeição, exploração e subalternidade reproduzidos no ambiente universitário. A diversidade cultural impõe o desafio de compreensão e reconhecimento de símbolos e significados subalternizados pelas concepções eurocêntricas que cimentam o ensino superior. Nesse sentido, de acordo com Menendez (2014), a universidade é impelida a reconhecer o ranço de forças colonizadoras que relegaram aos saberes indígenas um lugar hierarquicamente inferior. 


\section{A Associação de Acadêmicos indígenas da UnB (AAIUnB)}

Criada em 2008, a AAIUnB foi idealizada pelos estudantes indígenas, na época existia também a Associação dos Acadêmicos Indígenas do Distrito Federal (AAIDF). Questionados sobre as motivações para cria-la indicam que "o grupo mais atuante [na AAIDF] era aqui [na UnB] então, vimos a necessidade de mudar para a AAIUnB (Entrevista COM Suliete Gervásio, Maloca-UnB, 29.04.2017). Além de unidade, essa organização busca facilitar o diálogo institucional em torno das demandas indígenas no tocante à permanência e inserção diferenciada na universidade:

[...] depois que a gente chegou [em 2006], depois de todas as dificuldades [...] não só em disciplinas, mas de adaptação cultural [...] A gente viu, a primeira turma já tinha percebido a importância de ter uma organização. Porque através dessa organização a gente ia poder reivindicar com maior força [...] (Entrevista $\mathrm{n}^{\circ}$ 2, Maloca UnB, 26.04.2017).

Demarcada como organização político-organizativa, a AAIUnB amalgama os anseios dos estudantes indígenas e os apresenta nas instâncias universitárias. Nesse aspecto, destaca-se também o caráter estratégico, no que tange à força da união desses atores:

O papel da associação hoje é esse, construir uma política pública voltada especificamente para estudantes indígenas, seja da graduação ou da pós-graduação. Porque você vai se formar aqui, na graduação, e vai querer fazer um mestrado, então já estará incluído nessa política. Até hoje não tem, estamos nessa fase de construir junto (Entrevista $\mathrm{n}^{\circ} 1$, Maloca UnB, 26.07.2017).

A AAIUnB propõe a articulação indígena para demandar uma política universitária que reconheça e respeite as especificidades de cada povo indígena. Segundo afirmaram nas entrevistas, há experiências positivas individuais e isoladas que não devem ser confundidas com uma política institucional em andamento. Nas palavras de um indígena entrevistado:

[...] a gente está lutando para que a universidade tenha políticas específicas para estudantes indígenas [...] são as reivindicações, mas não tem nada formal. A nossa luta agora é essa: uma política específica para estudantes indígenas. A monitoria que a gente tem hoje não é a universidade que oferece. A monitoria que a gente tem é trabalho de um professor lá do Instituto de 
Biologia, professor Humberto (Entrevista $\mathrm{n}^{\circ}$ 2, Maloca UnB, 26.04.2017).

AAIUnB interpela à UnB propondo políticas que complementem os editais diferenciados de promoção ao ingresso dos indígenas ao ensino superior. Segundo os associados da AAIUnB, essas políticas institucionais voltadas à assistência aos estudantes novos e garantia de permanência para os veteranos. Nas narrativas é explicito o conhecimento acumulado e transmitido entre calouros e veteranos e a visão de longo prazo na agenda da AAIUnB.

A gente não tinha apoio para alimentação [bolsa], a primeira turma também não teve. Se conseguiu reduzir para cinquenta [centavos de real (SR)] e agora não paga nada [gratuidade no restaurante universitário]. E nós não tínhamos também apoio moradia [bolsa]. Foi uma luta nossa. E agora o grupo [AAIUnB] ganhou uma força maior também porque logo no início os estudantes da graduação não tinham tanto contato com os estudantes da pós-graduação (Entrevista $\mathrm{n}^{\circ} 2$, Maloca UnB, 26.06.2017).

AAIUnB reivindica políticas diferenciadas que reconheçam a diversidade étnica e cultural dos seus povos de origem, direito constitucional desde 1988, e ações de curto prazo como o acesso as bolsas alimentação e moradia já existentes na estrutura universitária. Contudo, essa associação também busca seu próprio fortalecimento. Nesse sentido deve ser entendido o depoimento acima que destaca a articulação e vinculação dos estudantes indígenas de pós-graduação. $O$ acesso desses povos ao mestrado de doutorado e seus desdobramentos tem sido abordado nos trabalhos do antropólogo indígena Felipe Cruz (2016), doutorando de antropologia na UnB.

\section{A Maloca UnB}

Os indígenas entrevistados relatam que a UnB não fez mudanças no sentido de acolher e reconhecer sua presença na instituição.

[...] nós nos encontrávamos ali naquelas árvores em frente ao $R U[$ [restaurante universitário]. Foi lá inclusive, de uma conversa lá, que nasceu a ideia de reivindicar um espaço nosso, onde pudéssemos estar tendo contato com os outros estudantes indígenas e também podendo praticar algumas manifestações culturais [...]. O pessoal Funiô, é cultural deles fumar o cachimbo. Então todo dia depois do almoço tem que ter o cachimbo. E esse espaço também é para isso. [...] Para fazer a 
apresentação de uma dança (Entrevista $\mathrm{n}^{\circ} 2$, Maloca UnB, 26.04.2017).

Propuseram, em agosto de 2009, a criação de um centro de Convivência indígena, que teria como objetivo principal oferecer condições espaciais e pedagógicas. A respeito da efetivação da construção, os indígenas assinalam que com base na proposta apresentada por eles a UnB elaborou o projeto da Maloca (Índios Online, 2016a).

Nessa perspectiva, Hauni Tupinambá, estudante indígena de Engenharia Florestal na UnB, assinala:

[...] Quando os estudantes [indígenas] chegaram aqui, notaram que quase todos os cursos tinham centros acadêmicos, que era um local em que os alunos se reuniam [...] Então precisávamos de um canto para reunir a gente indígena [...] E quando entraram os alunos de 2008 começou uma reivindicação maior, solicitando esse espaço, que tivesse um local para a gente se encontrar (Entrevista $n^{\circ} 3$, Maloca UnB, 29.04.2017).

A reivindicação por um espaço físico se tornou centralidade nas demandas dos estudantes indígenas da UnB.

[...] começamos a ir à reuniões com o reitor, solicitar esse espaço, porque já tinha CCN [centro de convivência negra] Aí nessas reuniões conseguimos uma sala no ICC Sul. Então ficamos usando como um espaço nosso, como um CA. Só que a gente não pode dizer CA porque CA é de cada curso, mas foi aí que começou a discussão pelo nome. A gente botou CAIN, que era CA Indígena. O primeiro nome foi CAIN (Entrevista $\mathrm{n}^{\circ} 2$, Maloca, 26.04.2017).

Inicialmente a UnB tomou medidas paliativas diante das reivindicações indígenas por um espaço que se equiparasse aos centros acadêmicos, mas que respeitasse as especificidades étnicas.

[era] a sala, a salinha que a gente chamava, apelidamos carinhosamente de CAIN, que é CA indígena, mas de CA não tinha nada assim, em comparação com outros $C A$ 's. A diferença é que era um espaço pequeno. Era um espaço de lazer, para estudo, monitoria, reuniões (Entrevista $\mathrm{n}^{\circ} 2$, Maloca UnB, 26.04.2017).

A idealização de um espaço físico com destaque das diferenças étnicas surgiu do dinamismo dos estudantes indígenas e da sensibilidade 
sociopolítica da gestão universitária no período 2008-2012. Afirmam que "o reitor José Geraldo [de Souza Junior], era muito chegado na gente, muito próximo. A gente conseguia marcar reunião, ele era muito aberto para causa indígena, para as minorias no geral, ele sempre falava para irmos dialogando" (Entrevista n 2, Maloca, 26.04.2017).

Sua construção, iniciada em 2010 e concluída em 2014, conta atualmente com salas de laboratório, salas de aula, redatário e pátio cerimonial. Incluise como uma de suas funcionalidades a atenção ao aluno indígena, no que concerne a tutoria, a monitoria e o acompanhamento ao desempenho escolar.

A construção não estava fluindo. Aí depois não tinha quem trabalhasse em Brasilia com madeira, uma empresa para poder construir. Porque tinha que seguir a norma direitinho, tinha que ter o engenheiro responsável, porque é um órgão federal. E isso conseguiu em 2012. Aí começou a construção, tiveram vários atrasos e a inauguração foi em 2014, em novembro [...] (Entrevista n², Maloca, 26.04.2017."

Na celebração de inauguração, foi realizada uma festa indígena. Os estudantes indígenas declararam ser um sonho realizado, resultado de sua luta e mobilização, que antes não tinha nenhuma sala no campus universitário (UnB, s/d). A Maloca UnB é o primeiro centro de convivência para a comunidade acadêmica indígena no Brasil (Guerreiros Potiguara, 18/04/2011). Nas narrativas dos autores indígenas Gabriel Gentil e Luís Lana a maloca enquanto construção étnica diferenciada é um lugar ritualístico, em que o mundo material e espiritual se associa. No início do mundo a primeira Maloca foi criada por Yepá, deusa da terra (MENENDEZ, 2014).

A adoção do simbolismo da Maloca no ambiente universitário do Campus Darcy Ribeiro estimula processos comunicativos que integrem o estudante indígena à faculdade (Índios Online 24/10/2009). Segundo Paz (2013), a Maloca é resultado de um projeto de futuro que possui significado simbólico porque projetado como um espaço concreto para construir novas relações que respeitem as diferenças e valorizem a diversidade de saberes.

A maloca é um ponto de encontro para fortalecer a cultura a identidade indígena. Foi a associação [AAIUnB] que foi na reitoria. Porque tem que ter toda aquela burocracia de você fazer um documento [...]. Para eles [gestão UnB], ganha mais força. $E$ ' um jogo político, entendeu? E assim, e hoje a gente tem, a associação conta com o apoio do grupo Moitará, que é um grupo de estudantes do Direito. Então a gente tem uma orientação 
agora bem melhor, até na elaboração de documentos [...]. A gente tem muitos apoios [também] do Instituto Autonomia (Entrevista n² 2, Maloca UnB, 26/04/2017).

Porem as narrativas dos entrevistados alertam que essa conquista do espaço físico não garante a sua presença na UnB, por isso a importância de políticas que institucionalizem o ingresso e permanência dos indígenas na UnB.

Quando a gente consegue alguma coisa, geralmente a gente dá uma estabilizada, a gente fica acomodada. A gente não pode, porque se a gente fica acomodado, as coisas desandam [...] estamos lutando para que a universidade tenha políticas específicas para estudantes indígenas. Porque o que tem são as reivindicações, mas não tem nada formal [precisamos que] a universidade tenha norma ou documento institucionalizado [regulamentando o] acompanhamento pedagógico $e$ psicológico [...] A nossa luta agora é essa: política específica para estudantes indígenas (Entrevista ${ }^{\circ} 2$, Maloca UnB, 26/04/2017).

Para os indígenas sua presença na UnB constitui um projeto político e pedagógico de longo prazo.

Esse espaço aqui [Maloca UnB] vai ficar pequeno, porque vai ter vestibular [novamente] e está prevendo a entrada de 80 indigenas por ano. [...] a primeira turma [de 2006] [...] fez 50\% do trabalho [...] E a nova galera que chegar, já vai ter um espaço, não vai se sentir tão perdido igual a gente quando entrou. Tem uma galera [AAIUnB] para orientar, não só na questão técnica mesmo da universidade, mas na questão de política (Entrevista $\mathrm{n}^{\circ}$ 2, Maloca UnB, 26/04/2017).

\section{Conclusão}

A presença indígena na UnB busca interpelar e constranger a gestão institucional universitária pelas omissões e descaso na ação cotidiana que vulnera os direitos étnicos reconhecidos constitucionalmente. Como espaço de transmissão e troca de saberes, o campo acadêmico ainda é permeado por racismo, preconceitos e estereótipos que fundamentam e disseminam 0 heroísmo branco e a civilização ocidental. Tal fato, ainda é evidenciado pela estrutura colonial, burocrática e racista que emoldura o projeto pedagógico institucional, os currículos, as políticas e decisões administrativas. $O$ racismo estrutural atravessa os projetos pedagógicos, por isso os saberes indígenas são negligenciados ou ignorados. 
Os dados empíricos aqui analisados confirmam que o acesso dos indígenas, embora importante não é o suficiente, sendo urgente o desenho e implementação de políticas que garantam a permanência e os direitos étnicos. No discurso dos indígenas da UnB, a defesa da institucionalização de políticas que garantam sua presença como projeto de longo prazo, ganha relevância diante da constatação de que recentemente a gestão universitária obstaculizou esse processo, especificamente durante o período 2012-2016.

A análise da idealização, construção e apropriação da Maloca-UnB e da trajetória da AAIUnB permite afirmar que os estudantes indígenas da UnB lideram dinâmicas que dialogam e contribuem com as demandas dos movimentos indígenas no Brasil. Os processos liderados pelos indígenas na UnB denotam lutas de longa duração que surgem para evidenciar as desigualdades sociais herdeiras do colonialismo.

\section{Referências}

ARCANJO, Julia. A luta pelo diploma e o diploma para a luta: educação superior para os povos indígenas. Monografia. Universidade de Brasília, Instituto de Ciências Sociais. Brasília, 2011.

BONFIL BATALLA, Guillermo. El pensamiento político de los indios en América Latina. Anuário Antropológico/79. Rio de Janeiro: Tempo Brasileiro, 1981.

CARVALHO, José Jorge de. Entrevista com o professor José Jorge de Carvalho. Revista Tempus - Acta de Saúde Coletiva. Brasília, v.6, n.1, 2014.

CAVIEDES, Mauricio. A escola intercultural indígena na Colômbia e no Brasil. Espaço Ameríndio, Porto Alegre, v. 10, n. 2, p. 224-252, jul./dez. 2016.

CELlARD, A. A análise documental. In: POUPART, J. et al. A pesquisa qualitativa: enfoques epistemológicos e metodológicos. Petrópolis, Vozes, 2008.

CODATO, Adriana. O espaço político segundo Marx. Crítica Marxista. São Paulo, n.32, 2011. p. 33-56.

COELHO, Elizabeth. Ações afirmativas e povos indígenas: o princípio da diversidade em questão. Políticas Públicas. Maranhão, v.10, n.2, 2006, p. 1-12.

CRUZ, Felipe. Indígenas antropólogos e o espetáculo da alteridade. Série Antropologia Vol. 456, Brasília: DAN/UnB, 2016, pp. 5-26.

FILHO, Gil. Por uma Geografia do Sagrado. Raega. Paraná, v.5, 2001. 
GORELIK, Adrian. La grilla en el parque: espacio público y cultura urbana em Buenos Aires (1837-1936). Buenos Aires: Universidad Nacional de Quilmes, 2004, p.19.

MIÈGE, Bernard. O espaço público: perpetuado, ampliado e fragmentado. Novos Olhares. São Paulo. Ano 7, n.14, 2004.

NIEDERAUER, Marcia. Universidade e universitários indígenas na internet: inclusões e exclusões no âmbito da representação. Tese de doutorado. Universidade Estadual de Campinas, Instituto de Estudos da Linguagem. Campinas, 2013.

QUIJANO, Aníbal. Colonialidade do poder, Eurocentrismo e América Latina. En: A colonialidade do saber: eurocentrismo e ciências sociais. Perspectivas latino-americanas. CLACSO, Consejo Latinoamericano de Ciencias Sociales. Buenos Aires, 2005, p. 117-138.

RESENDE, Viviane de Melo \& RAMALHO, Viviane. Ciência Social Crítica e Análise de Discurso Crítica. São Paulo: Contexto, 2006/1ª reimpressão 2009, p. 25-54.

SANTOS, Gersem. Indígenas no Ensino Superior: Novo Desafio para as Organizações Indígenas e Indigenistas no Brasil. In: SMILJANC, Maria Inês; PIMENTA, José; BAINES, Stephen. (Org.). Faces da Indianidade. led. Curitiba: Nexo Design, 2009, v1, p. $187-202$.

SILVA, Josinaldo Da; TARGINO, Nadyelle; CORRÊIA, Rilmara Araújo. Indígenas na universidade brasileira: sonho, esperança ou pesadelo? Tempus - actas de saúde coletiva, Brasília, v. 6, n.11, p. 109-120, 2012.

SOUSA, Josicélia do Nascimento Ramos, (2009). Os Desafios dos estudantes e das instituições no convênio- FUNAI - UNB. Monografia de Especialização, Universidade de Brasília, Brasília.

WALSH, Catherine. Interculturalidad crítica/pedagogia de-colonial. Revista de Educação Técnica e Tecnológica em Ciências Agrícolas, v. 3, n. 6, p. 25-42, 2012.

\section{Referências Documentais}

AAIUnB. Projeto Semana Indígena 2016. Brasília: AAIUnB. 2016.

GERVÁSIO, Suliete. Relatoria da Segunda Semana dos Acadêmicos Indígenas da UnB - Mesa de Debate Estudantes Indígenas: Avanços, Perspectiva e Desafios. Brasília: Maloca; 26/04/2016. 
APURINÃ, Francisco. Relatoria da Segunda Semana dos Acadêmicos Indígenas da UnB - Roda de conversa: Direitos Indígenas. Brasília: Maloca; 2016

UnB. Regras de convivência da Maloca 2015. Brasília: coordenação das questões indígenas; 2015.

\section{Sítios Eletrônicos (Links)}

G1 Notícias. UnB inaugura prédio de convivência multicultural para indígenas. http://brasil.noticias.voxquo.com/noticia-detalhe-media.asp ?id=1390028\&amp;t=UnB-inaugura-pr\%E9dio-de-conviv\%EAncia-multicultu ral-para-ind\%EDgenas. Acessado em: 20/09/2016 às 11:06

Cotidiano dos indígenas estudantes da UnB. http://cotidiano indigenaunb.blogspot.com.br/2010/04/entrega-do-projeto-de-construcaoda.html. Acessado em 22/10/2016

Índios Online. Encontro do reitor da Universidade de Brasília (UnB) e estudantes indígenas. http://www.ccn.unb.br/sobre-centro. Acesso em 27/11/2016. 2016b.

Maloca UnB. http://estudantesindigenasunb.blogspot.com.br/ Acessado em: 14/09/2016 às 17:31.

UnB. UnB Notícias. Povos Indígenas ganham espaço cultural. http://www.unb.br/noticias/unbagencia/unbagencia.php?id=2510Acessado em: 12/09/2016 às 22:19 